\title{
Ventricular hypoplasia in farmed Atlantic salmon Salmo salar
}

\author{
Trygve T. Poppe ${ }^{1, *}$, Torunn Taksdal ${ }^{2}$ \\ ${ }^{1}$ The Norwegian School of Veterinary Science, PO Box 8146, Dep., 0033 Oslo, Norway \\ ${ }^{2}$ National Veterinary Institute, PO Box 8156, Dep., 0033 Oslo, Norway
}

\begin{abstract}
Atlantic salmon Salmo salar L. parr and pre-smolts from 2 Norwegian hatcheries showed reduced weight gain, abnormal behaviour and signs of circulatory disturbances. Necropsy revealed conspicuous fat deposits around the heart to be the most consistent finding. Furthermore, the ventricle/atrium ratio was altered, with the size of the ventricle significantly smaller than normal in affected fish. Histology showed poor development or absence of the outer, compact myocardium, large numbers of fat cells and melanomacrophages in the epicardium, fibrosis, and inflammation of the compactum/spongiosum interphase. Nuclei of the inner spongious myocardium showed signs of compensatory hypertrophy. The cause(s) of this malformation is(are) unknown, but a high prevalence of other malformations in fish from the same population indicates high temperature during incubation of the eggs as a possible aetiology.
\end{abstract}

KEY WORDS: Salmo salar · Ventricular hypoplasia · Cardiac malformation

\section{INTRODUCTION}

Malformations in skeletal and soft tissues have been known to occur in feral and farmed fish for a very long time (Dawson 1964, 1966, 1971, Dawson \& Heal 1976). Their cause(s) may be multifactorial including microbiological, nutritional, hereditary, chemical, physical and environmental factors. Since the mid 1990s, increasing numbers of malformations have been recorded in farmed Atlantic salmon Salmo salar L. in Norway. These include swimbladder anomaly (Poppe et al. 1997), polycystic liver (Bruno \& Ellis 1986), situs inversus of the heart, hypoplasia/aplasia of septum transversum (Kaada \& Hopp 1995, Poppe et al. 1998) and several other conditions that are hitherto undescribed, e.g. reduced number of pyloric caecae, situs inversus of the liver and cranial and spinal disorders (authors' pers. obs.). In the winter and spring of 1997 , parr and pre-smolts with clinical signs of severe cardiac failure were reported by fish farmers and fish

*E-mail: trygve.poppe@veths.no health veterinarians in several smolt farms on the west coast of Norway. Autopsy revealed abnormal cardiac ventricle and severe oedema in affected fish. In this communication, the clinical manifestation and pathological findings associated with this anomaly called 'white heart' by the fish farmers are described.

\section{MATERIALS AND METHODS}

A total of 200 fish from 4 smolt farms in different regions in Norway were collected (see Table 1). Healthy and diseased individuals were sampled individually, based on clinical appearance from Farm A and Sampling No. 1 from Farm B. Healthy fish for reference were sampled from 2 unaffected farms (Farms C and D) and used as controls, while a random sampling after crowding of the fish was done in Sampling No. 2 in Farm B. All sampled fish were killed with an overdose of Benzocaine and examined immediately.

In 72 fish (38 diseased and 34 healthy controls), the liver and digestive tract were dissected out, the pericardial sac opened and the body wall cut away cra- 
Table 1. Salmo salar. Mean weights, condition factors and ratio between the lengths of the ventricle and the length of the atrium, measured as shown in Fig. 1, in diseased and healthy fish from Farms A, B, C and D. SD: sample standard deviation; nr: not recorded. * Significant difference, $\mathrm{p}<0.05$

\begin{tabular}{|c|c|c|c|c|c|c|c|}
\hline Farm & $\begin{array}{l}\text { Sampling } \\
\text { no. }\end{array}$ & $\begin{array}{c}\text { Clinical } \\
\text { appearance }\end{array}$ & $\begin{array}{l}\text { No. of } \\
\text { fish }\end{array}$ & $\begin{array}{l}\text { Mean weight (g) } \\
\text { (SD) }\end{array}$ & $\begin{array}{l}\text { Condition factor } \\
\text { (SD) }\end{array}$ & $\begin{array}{l}\text { No. of } \\
\text { hearts } \\
\text { measured }\end{array}$ & $\begin{array}{l}\text { Mean ratio, lengths of } \\
\text { ventricle/atrium } \\
\text { (SD) }\end{array}$ \\
\hline \multirow[t]{3}{*}{ A } & 1 & Diseased & 13 & $18.1(2.6)^{*}$ & $1.26(0.11)$ & 12 & $0.80(0.31)^{*}$ \\
\hline & & Healthy & 12 & $27.1(5.7)^{*}$ & $1.19(0.11)$ & 9 & $2.84(1.06)^{*}$ \\
\hline & 2 & Diseased & 11 & $14.9(2.7)$ & $1.22(0.13)$ & 11 & $0.91(0.31)$ \\
\hline \multirow[t]{5}{*}{ B } & 1 & Diseased & 15 & $46.5(6.6)^{*}$ & $1.13(0.12)^{*}$ & 15 & $0.84(0.26)^{*}$ \\
\hline & & Healthy & 15 & $56.5(7.2)^{*}$ & $0.95(0.07)^{*}$ & 15 & $4.41(1.33)^{*}$ \\
\hline & $2^{\mathrm{a}}$ & Hypoplasia & 5 & $46.4(6.5)^{*}$ & $1.24(0.09)^{*}$ & 0 & $\mathrm{nr}$ \\
\hline & & $\begin{array}{l}\text { Aplasia of septum } \\
\text { transversum }\end{array}$ & 5 & $57.8(9.2)$ & $1.15(0.04)$ & 0 & $\mathrm{nr}$ \\
\hline & & Healthy & 95 & $61.4(13.7)^{*}$ & $1.13(0.16)^{*}$ & 0 & $\mathrm{nr}$ \\
\hline $\mathrm{C}$ & 1 & Healthy & 10 & 17.0 & $1.02(0.08)$ & 10 & $1.64(0.71)$ \\
\hline $\mathrm{D}$ & 1 & Healthy & 19 & 28.32 & $1.15(0.07)$ & 0 & $\mathrm{nr}$ \\
\hline
\end{tabular}

nially to the dorsal fin before the head with cardiac appendages was fixed in $4 \%$ buffered formaldehyde for $48 \mathrm{~h}$. The in situ fixed heart (atrium, ventricle and bulbus arteriosus) was carefully dissected from the surrounding appendages. The total length of the heart (vertical axis from the top of the atrium to the apex of the ventricle), the (relative) length of the ventricle (apex to the atrioventricular sulcus) and the (relative) length of the atrium (top of the atrium to the atrioventricular sulcus) were measured by use of a Leitz dissection microscope equipped with a measuring graticule attached to the eyepiece. As the exact location of the atrioventricular junction was not evident due to fat deposition, the atrioventricular sulcus was therefore defined as the centre line of the atrioventricular fat deposit (see Fig. 1). Histological sections were made from the ventricle of all formalin-fixed fish from Farm A at locations I, II and III as shown in Fig. 1, processed routinely and stained with H\&E, Martius scarlet blue (MSB) and van Gieson stain (Bancroft \& Stevens 1990). Sections were also made from the liver, kidney and muscle from 10 affected fish and from 10 healthy controls. Bacteriological examination was performed routinely from affected fish by local fish health veterinarians using standard procedures according to fish health inspection manuals. Length (in $\mathrm{cm}$ ), weight (in $\mathrm{g}$ ) and the condition factor (weight in $\mathrm{g} /$ length in $\mathrm{cm}^{3} \times 100$ ) were recorded. The mean weight and condition factor in healthy fish were compared to the corresponding diseased fish by applying the Wilcoxon Rank Sum test (JMP, version 31.5, SAS Institute Inc.). The ratio between ventricle and atrium length was calculated. The mean ratio in diseased and healthy groups was compared as described above.

\section{RESULTS}

Clinical findings. Affected fish were typically darker than normal fish and exhibited moderate to severe distension of the abdomen with bilateral exophthalmia. These fish were less active than normal fish, stayed on the bottom of the tanks and had reduced stamina when chased with the fish net. Consequently, they were easy to catch. The fish farmers also reported that these fish were overrepresented amongst the daily mortalities. In Farms A and B, the weight of fish with ventricular hypoplasia was significantly lower than that of the healthy individuals, and they also had a higher condition factor (Table 1).

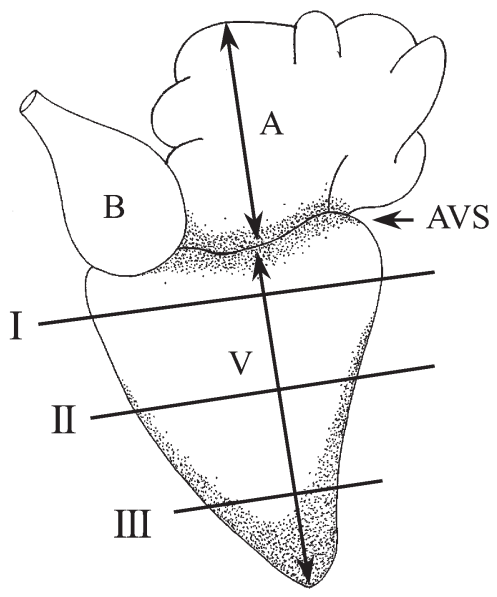

Fig. 1. Schematic diagram of the salmonid heart. A: atrial length, B: bulbus arteriosus, V: ventricular length, AVS: atrioventricular sulcus. Fat deposits typically occur in shaded areas. The locations of histological transverse sections are marked I, II and III 
Gross pathology. Characteristic external findings included dark coloration, exophthalmia and a swollen abdomen. In addition, there was water logging of the scale pockets in some fish, reflected in raised scales, a matt surface and water squirting from the surface when the skin was pressed. The majority of the affected fish had large amounts of ascitic fluid in the abdominal cavity. Five fish $(4.76 \%)$ with no septum transversum and 5 fish $(4.76 \%)$ with hypoplastic ventricle were found in the second sample from Farm B (Table 1).

The most characteristic changes were found in the heart. The ventricle appeared considerably smaller and more rounded than normal. A conspicuous layer of fat was present along the edges and apex of the ventricle and in the atrioventricular sulcus (Figs. 1 \& 2). In several cases, these fat deposits more or less covered the ventricle completely. In some hearts, there were obvious accumulations of melanomacrophages in the epicardium, giving the ventricular wall a 'dirty' appearance. In normal fish, the bulbus arteriosus is typically pear-shaped and white. In affected fish it appeared more tubular and thinner than normal and had a clear, red colour.

The measurements taken revealed a significant difference in the ventricle:atrium ratio in affected and normal hearts. In healthy fish, the ventricle:atrium ratio was on average 5:1 and always more than 2, while in affected fish, the ventricle was shorter or equal in length to the atrium and the ventricle:atrium ratio was always less than 1.4 (Table 1).

Histopathology. Histology of affected hearts revealed that the shape of a cross section of the ventricle changed from the normal triangular shape, to a more rounded appearance (Fig. 3). The outer compact layer of the ventricular myocardium was considerably thinner than normal controls, and was completely absent in some areas. The MSB and van Gieson stains revealed considerable amounts of connective tissue between the inner spongious and rudimentary outer compact myocardium (Fig. 4). Fat cells were abundant in the epicardium, in particular near the rounded edges in the cross sections of the ventricle. The melanization of the epicardium seen macroscopically was confirmed histologically by the abundant presence of melanomacrophages, particularly near the atrioventricular sulcus and in areas where the outer compact muscle layer was absent. In the epicardium and in areas where the outer compact muscle layer was thin or absent, there was also a heavy infiltration of lymphocytes and macrophages. The nuclei of the inner spongious myocardium were enlarged to a variable extent and in some hearts there was also patchy degeneration of the inner myocardium. The walls of the bulbus arteriosus were thinner than normal; otherwise no other abnormalities were found. No pathological changes were observed in other organs.

Microbiology. No bacteria were isolated.

\section{DISCUSSION}

Hearts of salmonids may undergo morphological changes during the life cycle of the fish and may also show considerable variation depending on gender and habitat. The mass of outer compact myocardium may vary considerably depending on stage of maturation, sex, breed, temperature and habitat. Graham \& Farrell (1992) showed that in rainbow trout Oncorhynchus mykiss the amount of outer compact myocardium was significantly higher in anadromous and farmed fish than in resident lake-dwelling individuals. Also, male fish had significantly larger hearts than female fish in

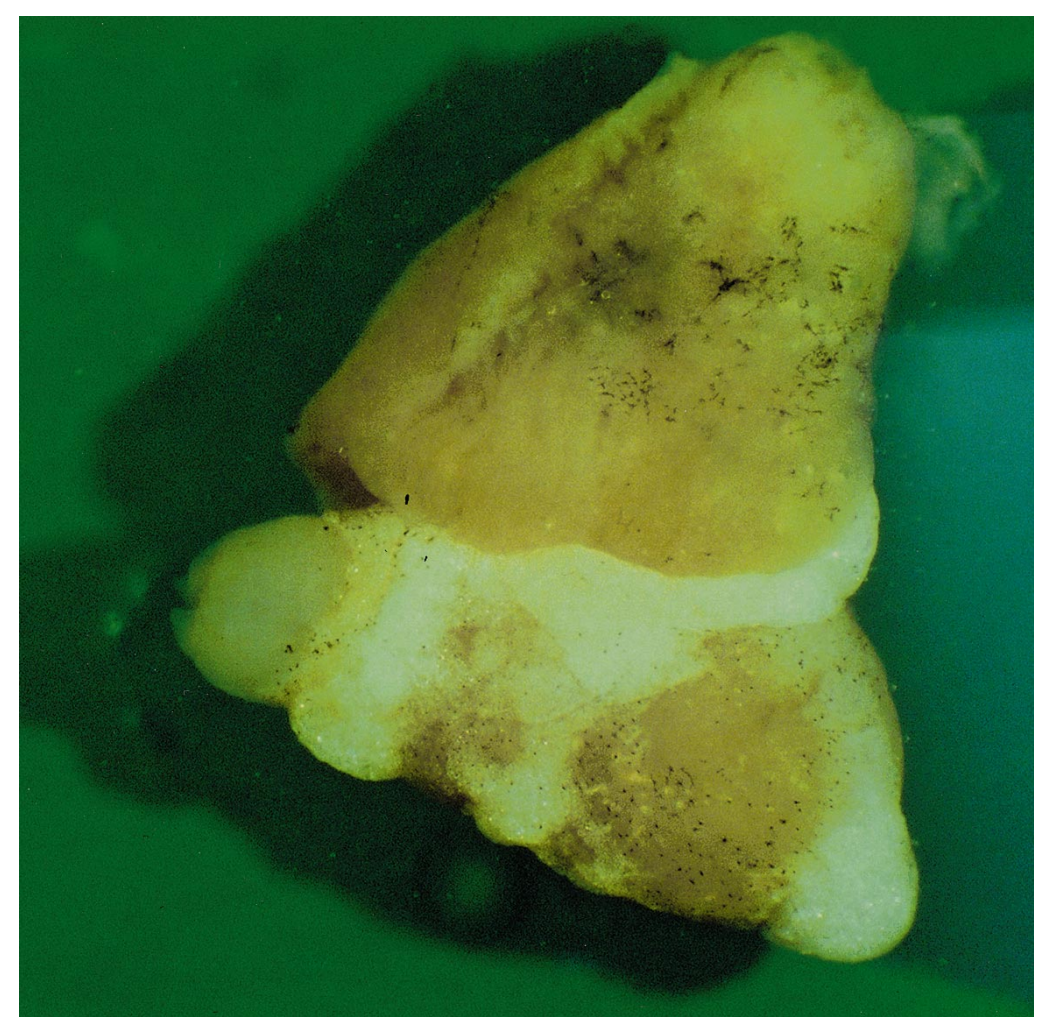

Fig. 2. Salmo salar. Heart with characteristic fat deposits in the atrioventricular sulcus and near the apex. The atrium is enlarged and there are melanin deposits in the epicardium 


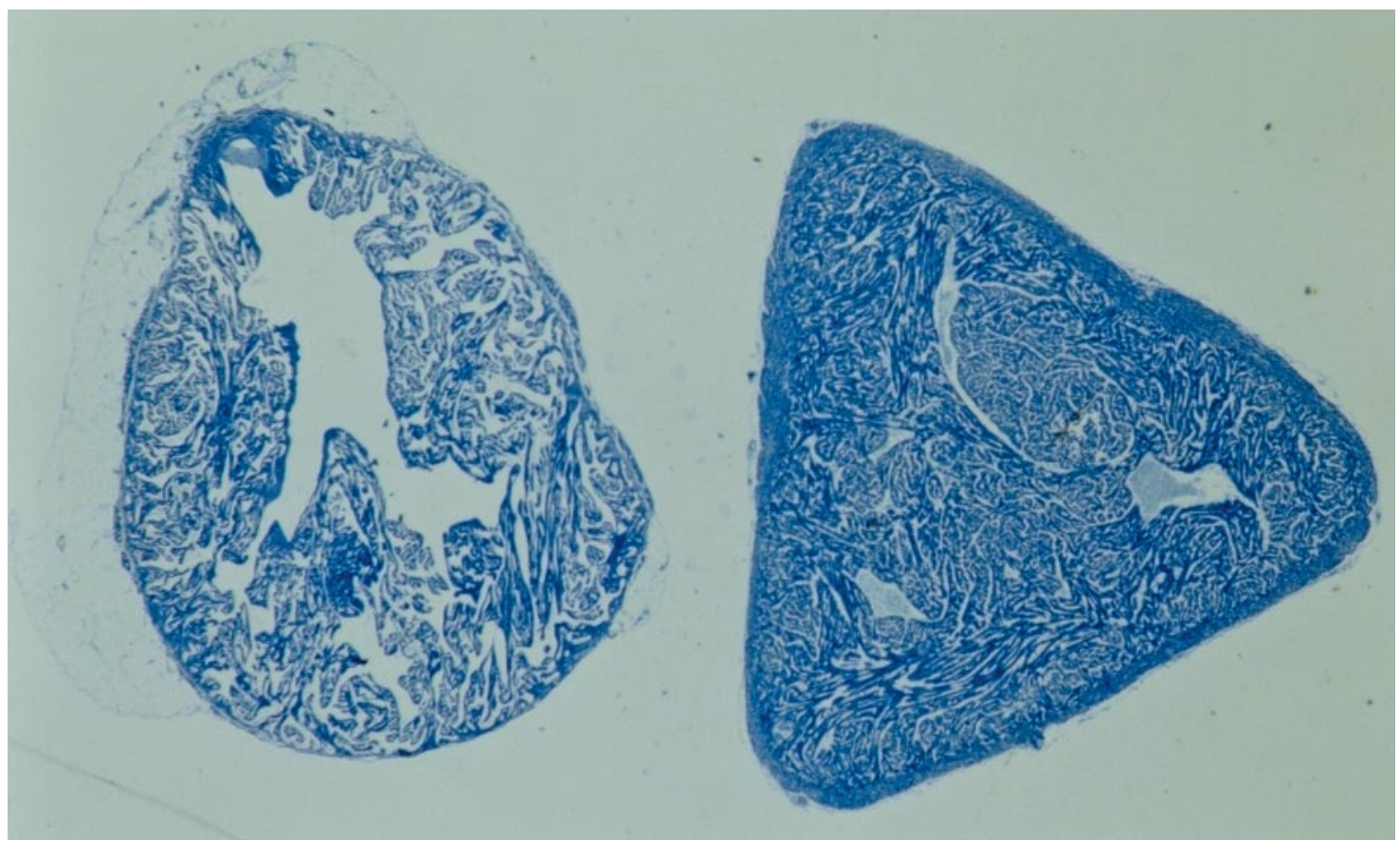

Fig. 3. Salmo salar. Histological appearance of the ventricle of a normal parr (right) located adjacent to a parr with hypoplastic ventricle (left). Notice rounded appearance and complete absence of outer, compact myocardium in the latter. Section at location II in Fig. 1. Stained with methylene blue, low magnification

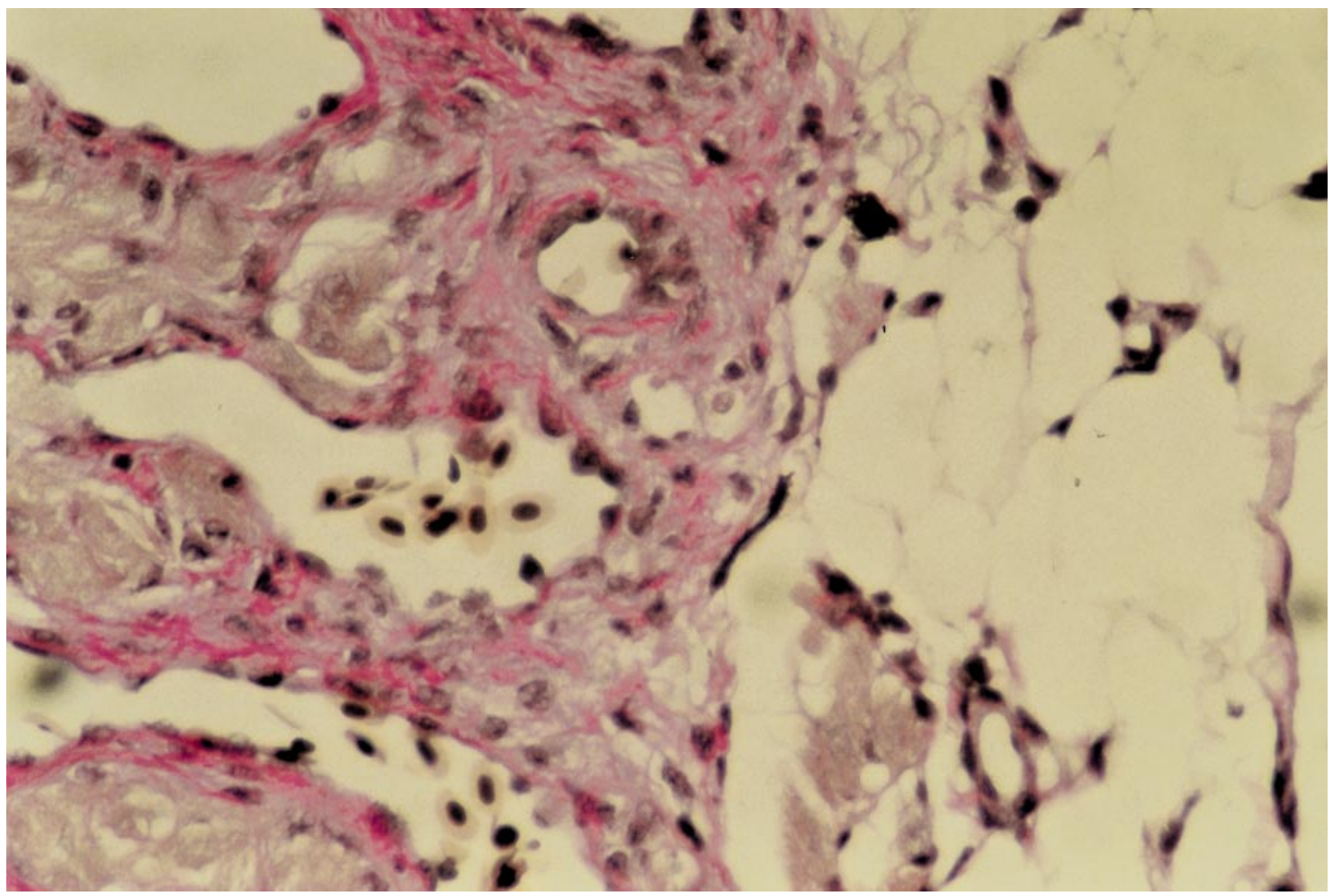

Fig. 4. Salmo salar. Detail of ventricle wall showing the interphase between inner spongious myocardium (left) and epicardium. Notice absence of outer compact myocardium, copious amounts of fat, melanomacrophages and connective tissue (red). Section at location II in Fig. 1. van Gieson stain, ×400 
all investigated groups (farmed, lake-dwelling and anadromous). The cardiac changes described in this work are clearly beyond these normal variations and must be considered as pathological. This is also reflected in the clinical manifestation of cardiac failure and increased mortality.

Apart from 2 recent reports (Amin \& Poppe 1989, Kaada \& Hopp 1995) primary cardiac abnormalities have not been recorded in farmed Atlantic salmon in Norway. In recent years, several different skeletal and soft tissue abnormalities have been of concern to fish farmers and fish health personnel. These include spine and cranial malformations (Bruno \& Poppe 1996), swimbladder abnormality (Poppe et al. 1997) and deformed hearts and abnormal pericardial cavity (Kaada \& Hopp 1995, Poppe et al. 1998). The causes of these abnormalities are probably multifactorial and may (in part) be the result of altered management practices. For example, increased temperature during incubation of salmon eggs is used to accelerate the embryonic development, resulting in earlier first feeding, a longer growth cycle and consequently larger smolts. It has been demonstrated recently by Bæverfjord et al. (1997) that a temperature increase from 8 to $10.4^{\circ} \mathrm{C}$ or more during the incubation of Atlantic salmon eggs increased significantly the number of fish with shortened operculae, and that a temperature increment from 7.4 to $9.8^{\circ} \mathrm{C}$ increased the prevalence of septum transversum aplasia (Bæverfjord pers. comm. 1999).

In Atlantic salmon, the pericardial cavity and heart tube develop early in embryonic ontogeny and spontaneous cardiac contractions begin later (Gorodilov 1996). Increased temperature during this period may alter the normal development of the heart and adjacent structures. The high prevalence $(4.76 \%)$ of fish with aplastic septum transversum concomitant with ventricle hypoplasia in the random sample from Farm B was similar to the abnormalities described by Kaada \& Hopp (1995) and Poppe et al. (1998) and may indicate a connection between the 2 abnormalities.

The primary lesion described in affected fish is most likely the hypoplasia/aplasia of the outer, compact ventricular myocardium. This is the most important contractive force in the circulatory system of salmonids and any dysfunction will be reflected in compensatory hyperplasia of the spongious inner myocardium and altered tension resulting in chronic inflammation and circulatory dysfunction. The rounded shape of hearts with absent outer compact myocardium will also decrease the effectiveness of the cardiac pump compared to the optimal triangular ventricular shape in normal fish (Farrell \& Jones 1992, Agnisola \& Tota 1994), further contributing to circulatory breakdown and reduced endurance in affected fish.
Although the exact cause(s) of this cardiac anomaly is(are) unknown, a link between other anomalies and this condition cannot be excluded. The fish described in this paper had been subject to the same high temperature regime as fish in populations with a high prevalence of absent septum transversum and no other plausible explanations can be suggested. Increased temperature during incubation has been shown to induce twin malformation in chum salmon Oncorhynchus keta (Yamamoto et al. 1996), possibly as a result of mechanical interference during the early phase of embryonic development. The ventricular hypoplasia presented here and other man-made anomalies in farmed fish should evoke some ethical concern among fish health personnel.

Acknowledgements. Acknowledgements are due to our colleagues Drs Inge Kaada, Brit Tørud, and Asgeir Østvik for assistance in sampling of fish and for providing valuable background information. Thanks are also due to May Britt Johansen for excellent technical assistance.

\section{LITERATURE CITED}

Agnisola C, Tota B (1994) Structure and function of the fish cardiac ventricle-flexibility and limitations. Cardioscience 5:145-153

Amin AB, Poppe TT (1989) Subendocardial fibroelastosis in Atlantic salmon: a case report. Bull Eur Assoc Fish Pathol 9:86-87

Bæverfjord G, Lein I, Åsgård T, Rye M (1997) Shortened operculae in Atlantic salmon (Salmo salar L.) fry reared at high temperatures. Abstract, Eur Assoc Fish Pathol, VIIIth International Conference, Edinburgh

Bancroft JD, Stevens A (1990) Theory and practice of histological techniques, 3rd edn. Churchill Livingstone, Edinburgh

Bruno DW, Ellis AE (1986) Multiple hepatic cysts in farmed Atlantic salmon, Salmo salar L. J Fish Dis 9:79-81

Bruno DW, Poppe TT (1996) A colour atlas of salmonid diseases. Academic Press, London

Dawson CE (1964) A bibliography of anomalies of fishes. Gulf Res Rep 1:308-399

Dawson CE (1966) A bibliography of anomalies of fishes. Gulf Res Rep (Suppl 1) 2:169-176

Dawson CE (1971) A bibliography of anomalies of fishes. Gulf Res Rep (Suppl 2) 3:215-239

Dawson CE, Heal E (1976) A bibliography of anomalies of fishes. Gulf Res Rep (Suppl 3) 5:35-41

Farrell AP, Jones DR (1992) The heart. In: Hoar WS, Randall DJ, Farrell AP (eds) Fish physiology, Vol XII, Part A. The cardiovascular system. Academic Press, San Diego, p 1-24

Gorodilov YN (1996) Description of the early ontogeny of the Atlantic salmon, Salmo salar, with a novel system of interval (state) identification. Environ Biol Fish 47:109-127

Graham MS, Farrell AP (1992) Environmental influences on cardiovascular variables in rainbow trout, Oncorhynchus mykiss (Walbaum). J Fish Biol 41:851-858

Kaada I, Hopp P (1995) Laks med deformerte hjerter og misdannede hjertesekker (Atlantic salmon with deformed heart and abnormal pericardial cavity). Bull Norw Vet Med Assoc 107:773-776 
Poppe TT, Hellberg H, Griffiths D, Meldal H (1997) Swimbladder abnormality in farmed Atlantic salmon Salmo salar. Dis Aquat Org 30:73-76

Poppe TT, Midtlyng P, Sande RD (1998) Examination of abdominal organs and diagnosis of deficient septum transversum in Atlantic salmon (Salmo salar L.) using diagnos-

Editorial responsibility: David Bruno,

Aberdeen, Scotland, UK tic ultrasound imaging. J Fish Dis 21:67-72

Yamamoto TS, Kobayashi W, Kuramoto T (1996) Twin malformation induced in chum salmon eggs by elevated water temperature, with a suggestion as to its mechanism. Can J Zool 74:485-491

Submitted: February 16, 2000; Accepted: April 29, 2000 Proofs received from author(s): July 10, 2000 